\title{
Expression of Bacillus ginsengihumi M2.11 bacterial phytase by recombinant Pichia pastoris strains
}

\author{
Daria L. Itkina*, Aliya D. Suleymanova, and Margarita R. Sharipova \\ Kazan Federal University, 18 Kremlyovskaya street, Kazan 420008, Russian Federation
}

\begin{abstract}
Phytic acid is the main storage form of organic phosphorus. Due to its structural features, phosphorus in phytate is inaccessible for assimilation by animals. Moreover, remaining inaccessible reservoir of phosphorus for animal nutrition, phytic acid is capable of forming insoluble complex salts, which lead to soil and water pollution. Microbial enzymes - phytases, capable of decomposing phytic acid to organic phosphorus are being used as feed additives in animal nutrition to solve this problem. Thus, search and development of technologies for the production of enzymes on an industrial scale are the most urgent. Methylotrophic yeast $P$. pastoris are widely used in biotechnology, as an efficient system for the recombinant proteins expression. They have many advantages, including rapid growth on inexpensive media, a wide range of molecular tools for genetic manipulation in optimizing production processes, they are safe for humans and animals, carry-out many posttranslational modifications and produce recombinant proteins intracellularly or extracellularly within a short period of time. It was found that the recombinant P. pastoris strains pPINK-LC- $\alpha-M F$-phyC, pPINKHC- $\alpha$-amyl -phyC, pPINK-LC- $\alpha$-amyl -phyC, pPINK-HC- $\alpha$-MF -phyC are able to produce and to secrete $B$. ginsengihumi bacterial phytase $\mathrm{M} 2.11$ phyC. The maximum activity was observed in the pPINK-LC- $\alpha$-MF strain - 2.6 (U / mg). Recombinant B. ginsengihumi M 2.11 phytases exhibited high activity in a wide $\mathrm{pH}$ range from 2.5 to 9.0 . The MF-phyC-HC construction is $\mathrm{pH}$ stable. The temperature optimum of all recombinant phytases corresponds to $37^{\circ} \mathrm{C}$; recombinant phytases retain their activity in the range from -80 to $90 \mathrm{C}$.
\end{abstract}

\section{Introduction}

Plant foods contain high levels of phytic acid and related salts called phytates. Phytates represent the main form of phosphorus storage in mature grains and seeds. The phytate content of cereals, legumes and oilseeds varies widely depending on botanical diversity and environment. Phytic acid chelates cations, forming insoluble complexes with minerals in the upper gastrointestinal tract and cannot be digested or absorbed by animals and humans due to the absence of intestinal phytase enzymes [1].

\footnotetext{
*Corresponding author: laia9301@mail.ru
} 
Phytases - are a class of phosphatases that sequentially hydrolyze phytic acid to less phosphorylated myo-inositol, with the release of inorganic phosphate [2]. Monogastric animals such as pigs, poultry and fish cannot effectively use phytate-bound phosphorus in plant-based feeds due to the limited activity of endogenous intestinal phytates. Poor absorption of phytate, in turn, increases the cost of animal husbandry, since an additional source of phosphorus is needed as a feed additive to meet the nutritional needs of the animal. In addition, phytic acid can cause environmental pollution. It forms stable complexes with minerals and proteins in the digestive tract, reducing their bioavailability for animals, and excreted with feces, they disrupts the balance of ecosystems, causing eutrophication of water [3].

One of the important tasks in biotechnology is the optimization of pathways for the industrial production of enzymes, including phytases. One of the ways to solve this problem is to create a stable phytase expression system based on the yeast - Pichia pastoris. P. pastoris carry-out many post-translational modifications and produce recombinant proteins intracellularly or extracellularly within a short period of time. Due to these properties, the $P$. pastoris yeast has become the most preferred host organism for various types of biotechnology. The aim of this work was to evaluate the activity of Bacillus ginsengihumi M 2.11 phytase in a heterologous expression system based on the P. pastoris yeast.

\section{Materials and methods}

We used a recombinant $E$. coli $\mathrm{DH} 5 \alpha$ bacterial strain carrying the pUC57 plasmid containing the $B$. ginsengihumi M 2.11 phyC phytase gene sequence optimized for yeast expression. The sequence of own signal peptide was excluded. C-terminal histidine (Histag) tag was added to the structural region of the gene in order to detect the protein during immunoblotting and purify it from the culture liquid of yeast by affinity chromatography. The integrative yeast vectors pPINK-HC (high copy vector) and pPINK-LC (low copy vector) (Invitrogen) were used to clone the optimized bacillary phytase gene into the yeast genome. Signal peptide sequences of $\alpha$-amylase ( $\alpha$-amyl) and $\alpha$-matting factor $(\alpha-\mathrm{MF})$ (Invitrogen) were used for extracellular expression. Methylotrophic yeast $P$. pastoris protease-deficient strains were used to transform the genetic (invitrogene).

BMGY medium (Buffered Glycerol-complex Medium, Invitrogen) was used for biomass accumulation of the recombinant $\mathrm{P}$. pastoris: $1 \%$ yeast extract, $2 \%$ peptone, 100 $\mathrm{mM}$ potassium phosphate ( $\mathrm{pH}$ 6.0), 1.34\% YNB (Yeast Nitrogen Base) , 0.00004\% biotin, $1 \%$ glycerol.) BMMY (Buffered Methanol-complex Medium, Invitrogen) was used for the induction of protein expression by the recombinant $\mathrm{P}$. pastoris: $1 \%$ yeast extract, $2 \%$ peptone, $100 \mathrm{mM}$ potassium phosphate ( $\mathrm{pH} 6.0$ ), 1.34\% YNB, $0.00004 \%$ biotin, $0.5 \%$ methanol. One colony of yeast transformants was transferred into $10 \mathrm{ml}$ of BMGY medium and grown in $150 \mathrm{ml}$ flasks for $1-2$ days at $28^{\circ} \mathrm{C}$ and $300 \mathrm{rpm}$. Then the cells were pelleted at $1500 \mathrm{rcf}$ for $5 \mathrm{~min}$, the supernatant was discarded. To induce protein expression, the cells were resuspended in $2 \mathrm{ml}$ of BMMY medium and grown at $28^{\circ} \mathrm{C}$ and $300 \mathrm{rpm}$ for 24 hours. Then, $40 \%$ methanol was added to the medium in a volume of $100 \mu \mathrm{l}$ per $1 \mathrm{ml}$ of the medium and grown for another 24 hours. After that, the culture was centrifuged at $1500 \mathrm{rcf}$ for $10 \mathrm{~min}$, the resulting supernatant was frozen in liquid nitrogen and stored at $-20^{\circ} \mathrm{C}$.

Protein electrophoresis. Separation of proteins by weight was carried out under denaturing conditions in the presence of SDS in $12.5 \%$ polyacrylamide gel (PAGE) according to Laemmli's method.

Determination of phytase assay. The enzyme activity was determined by the Greiner method by the amount of released phosphorus during hydrolysis of the sodium phytate substrate (Sigma Aldrich, United States) [4Greiner, 2004]. The reaction mixture of the experimental sample contained $55 \mu \mathrm{l}$ of $10 \mathrm{mM}$ sodium phytate substrate, $125 \mu \mathrm{l}$ of 100 
mM M Tris-HCl buffer with $\mathrm{pH} 8.0,35 \mu \mathrm{l}$ of enzyme, $20 \mu \mathrm{l}$ of $10 \mathrm{mM} \mathrm{CaCl} 2$ solution. The mixture was incubated at $37^{\circ} \mathrm{C}$ for 1 hour. In the control sample containing $50 \mu \mathrm{l}$ of substrate $10 \mathrm{mM}$ sodium phytate, $20 \mu \mathrm{l}$ of $10 \mathrm{mM} \mathrm{CaCl} 2$, and $125 \mu \mathrm{l}$ of $100 \mathrm{mM}$ M Tris$\mathrm{HCl}$ buffer with $\mathrm{pH} 8.0$, the enzyme was added after incubation at $37^{\circ} \mathrm{C}$. The reaction was stopped by adding $15 \%$ TCA, then $900 \mu \mathrm{l}$ of a freshly prepared AAM solution ( $10 \mathrm{mM}$ ammonium molybdate, $5 \mathrm{~N} \mathrm{H} 2 \mathrm{SO} 4$ solution and acetone in a ratio of 1: 1: 2) was added. After that, $60 \mu \mathrm{l}$ of $1 \mathrm{M}$ citric acid was added to the mixture. The absorption of the experimental and control samples was measured on a spectrophotometer at $355 \mathrm{~nm}$ in a 1 $\mathrm{cm}$ cuvette. A unit of activity was defined as the amount of enzyme that cleaved sodium phytate to form $1 \mu \mathrm{M}$ inorganic phosphate in one minute. Phytase assay was calculated using the formula:

$\mathrm{U}=(\mathrm{EA}-\mathrm{EB}) * \mathrm{~F} *$ dilution, where EA - values of Dopt experience, EB - values of Dopt control,

$\mathrm{F}=1 / \mathrm{t} * 1 /(\mathrm{d} * \varepsilon) *(\mathrm{~V}$ total $) /(\mathrm{V}$ farms $)$, where $\mathrm{d}=1 \mathrm{~cm}$ (cuvette $), \varepsilon=8.7 \mathrm{~cm} 2$ (extinction coefficient of sodium phytate substrate).

To study the $\mathrm{pH}$ stability, the enzyme was incubated at $37^{\circ} \mathrm{C}$ for $1 \mathrm{~h}$ in buffer at different $\mathrm{pH}$ values (from 2.5 to 9.0 ). The enzyme activity was determined according to the standard method, the following buffers were used: $100 \mathrm{~mm}$ glycine- $\mathrm{HCl}$ ( $\mathrm{pH} 2.5$ to 3.5), $100 \mathrm{~mm}$ sodium acetate (pH 3.5 to 5.5), $100 \mathrm{~mm}$ Tris-acetic acid (pH 5.5 to 7.5), $100 \mathrm{~mm}$ Tris $-\mathrm{HCl}(\mathrm{pH} 7.5$ to 9.0$)$.

The $\mathrm{pH}$ optimum of the enzyme activity was determined by the hydrolysis of sodium phytate at $37^{\circ} \mathrm{C}$ in the $\mathrm{pH}$ range from 2.5 to 9.0 with a step of $0.5 \mathrm{pH}$ units. The temperature optimum of the enzyme action was determined by hydrolysis of sodium phytate in $100 \mathrm{mM}$ Tris- $\mathrm{HCl}$ buffer, $\mathrm{pH} 9.0$, in the temperature range from 25 to $80^{\circ} \mathrm{C}$.

Determination of thermal stability was carried out by preliminary incubation of the enzyme for $1 \mathrm{~h}$ at temperatures from $-80^{\circ} \mathrm{C}$ to $90^{\circ} \mathrm{C}$, after which the activity of phytase was determined by hydrolysis of phytate according to the standard method.

The results are presented as the mean of two independent experiments, taking into account the standard deviation.

\section{Results and discussion}

The most optimal eukaryotic expression systems for the production of recombinant proteins are yeast systems, in particular, P. pastoris. Yeasts provide a high level of expression of heterologous proteins, which in P. pastoris is achieved due to the presence of a strong AOX1 promoter. Recombinant strains of P. pastoris pPINK-HC / LC -phyC were obtained by integration into the genome of genetic constructs based on integrative yeast plasmids pPINK-LC- $\alpha$-MF-phyC, pPINK-HC- $\alpha$-MF-phyC, pPINK-LC- $\alpha$-amyl-phyC and pPINKHC- $\alpha$-amyl-phyC containing the $B$. ginsengihumi M 2.11 alkaline phytase gene optimized for expression in yeast and the $\alpha$-amylase and $\alpha$-mating factor signal peptide sequences for protein extracellular expression. It was of interest to study and compare the properties of the recombinant phytases $\alpha$-MF-phyC-LC, $\alpha$-MF-phyC-HC, $\alpha$-amyl-phyC-LC, and $\alpha$-amylphyC-HC expressed by the yeast $P$. pastoris.

The extracellular accumulation of the expressed protein in the culture medium by the recombinant $P$. pastoris strains was checked by protein electrophoresis in PAGE and phytase assay. The culture liquid of yeasts, secreting recombinant phytase AgpP from Pantoea brenneri with a molecular weight of $70 \mathrm{kDa}$, was used as a positive control. After 24 hours of methanol induction, recombinant protein was detected in the PAGE of culture liquid of P.pastoris - specific band with apparent molecular mass of $70 \mathrm{kDa}$ was observed.

In their study, J. M. Viader-Salvadó et al compared the properties of recombinant betapropeller phytases of the Bacillus secreted in P. pastoris yeast expression systems. Three 
recombinant phytases (FTE, FTEII and FBA) showed a smear on SDS-PAGE gel ranging from 45 to $66 \mathrm{kDa}$. [5]

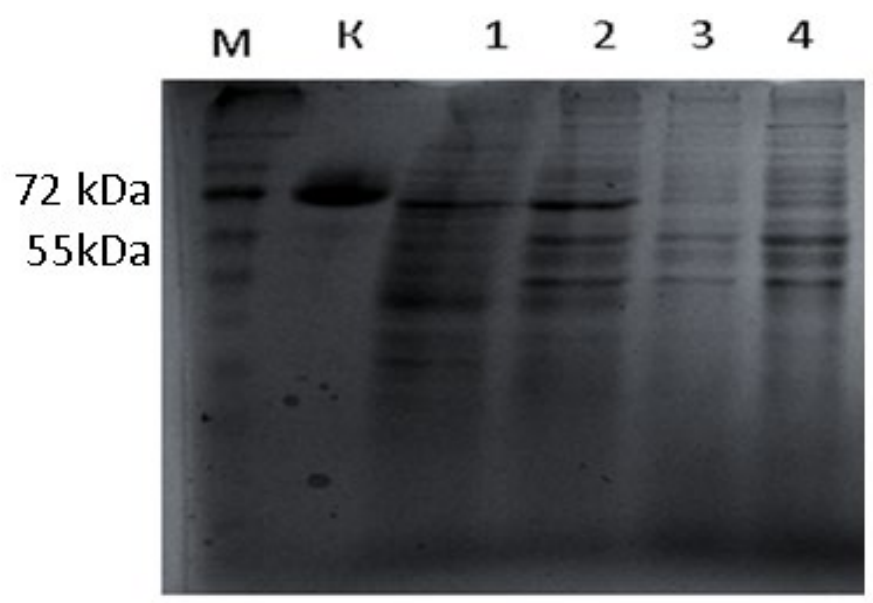

Fig. 1. Protein electrophoresis of the culture fluid (CL) of the P. pastoris yeast. $\mathrm{M}$ - protein marker; 1MF-phyC-HC, 2-MF-phyC-LC, 3-a-amylase-phyC-LC, 4- a-amylase-phyC-HC. K - positive control (QOL of yeast with the pPINK-HC / agpP construct).

The phytase activity of the secreted enzyme was measured by the hydrolysis of the substrate - sodium phytate. CL samples of the recombinant $P$. pastoris were taken $24 \mathrm{~h}$ after induction with methanol. The strains carrying the pPINK-LC- $\alpha-M F-p h y C$ construct showed a maximum activity of $2.6(\mathrm{U} / \mathrm{mg})$ at $24 \mathrm{~h}$ after induction. The strains with the pPINK$\mathrm{HC}-\alpha-\mathrm{MF}-$ phyC construct had an activity of $2.1 \mathrm{U} / \mathrm{mg}$. The strains carrying the pPINKLC- $\alpha$-amyl-phyC and pPINK-HC- $\alpha$-amyl-phyC constructs had their maximum activity of 2.1 and $1.9(\mathrm{U} / \mathrm{mg})$, respectively. Our results are consistent with the data obtained for recombinant Bacillus phytases expressed in P. pastoris. The B. subtilis VTT E-68013 strain showed a $50 \%$ greater extracellular enzyme activity $(1.2 \mathrm{U} / \mathrm{mg})$ than the GS115-PhyC strain at $24 \mathrm{~h}$ after induction [6]. The B. amyloliquefaciens KM71FBA strain by $48 \mathrm{~h}$ of induction showed phytase activity in the range of 0.8 to 3.4 ( $\mathrm{U} / \mathrm{mg})$ [5].

In the digestive tract of poultry, enzyme will pass through the digestive sections, the $\mathrm{pH}$ of which is significantly differ from each other. To show its maximum activity, the enzyme should not be inactivated under the influence of different $\mathrm{pH}$ values in the digestive tract. Thus, an increase in stability, both at acidic and alkaline values of the medium, is of practical importance, since it is necessary to take into account the low $\mathrm{pH}$ level (4-5) in the anterior (cardiac) part of the stomach, as well as in the glandular and muscular stomach ( $\mathrm{pH}$ 2-5) of the gastrointestinal tract of chicken [8].

The $\mathrm{pH}$ stability of the recombinant PhyC phytase was determined in the $\mathrm{pH}$ range from 2.5 to 9.0 . It was found that all enzymes retained about $90 \%$ of their activity at $\mathrm{pH}$ values from 7.5 to 9.0 , while at acidic values the activity of phytases was not more than $80 \%$ (Figure 2). 


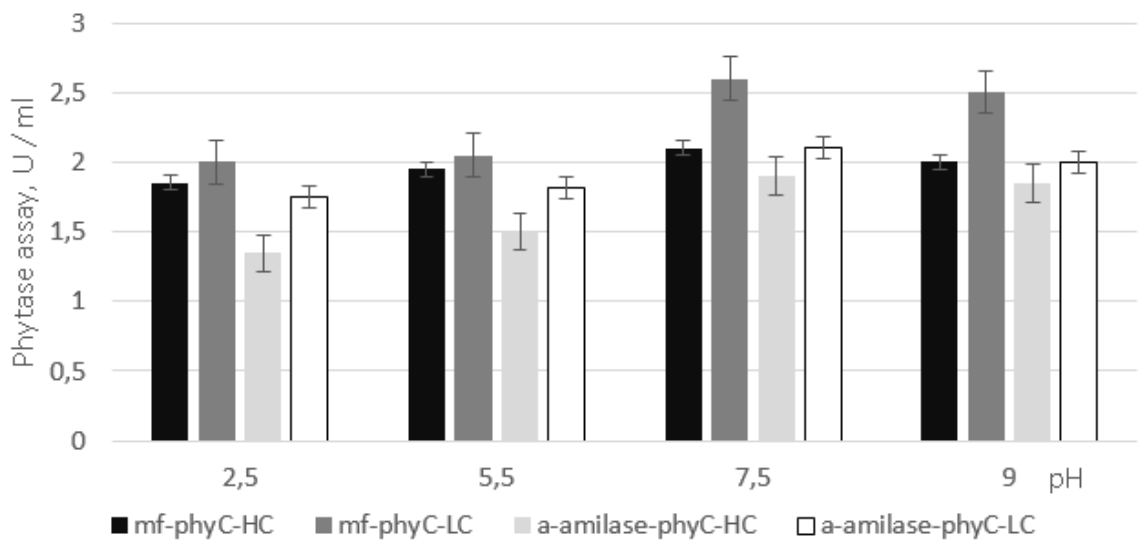

Fig. 2. $\mathrm{pH}$ stability of recombinant phytases. The activity of enzymes incubated at pH 9.0 was taken as $100 \%$.

All enzymes containing the a-amylase signal peptide exhibited lower activity compared to enzymes with the $\alpha$-mating factor signal peptide. At the same time, the phytases MFphyC-HC and a-amylase-phyC-LC were more stable than the phytases MF-phyC-LC and aamylase-phyC-HC, as they retained approximately the same activity at all $\mathrm{pH}$ values.

Thus, it was found that the greatest activity of phytase exhibited at alkaline $\mathrm{pH}$. Bacillus phytases are beta propeller phytases that require calcium ions for their activity and stability, exhibit an optimal $\mathrm{pH}$ of 6.0 to 9.0 and tend to be suitable for using as feed additives in animals with a neutral $\mathrm{pH}$ of digestive tract [6]. Our data are consistent with the data obtained by J. M. Viader-Salvadó et al - three recombinant phytases showed maximum activity at pH 7.5 (FTE and FBA) and 9.0 (FTEII). [5].

Each enzyme is stable at its corresponding $\mathrm{pH}$ values, since changes in the $\mathrm{pH}$ of the medium change the conformation of the protein molecule, its active center and, consequently, the ability to carry out catalysis [8]. Thus, all enzymes showed the greatest activity at alkaline values. Based on their $\mathrm{pH}$ profiles, phytases can be said to be suitable as feed additives for animals with a neutral-basic digestive tract as well as for animals with acidic $\mathrm{pH}$ values. Thus, the enzymes will be active during the dephosphorylation of phytate throughout the entire gastrointestinal tract of chickens, which makes it possible to use them as a feed additive, since they will not be inactivated while passing through the gastrointestinal tract of chickens.

Temperature optimum. The internal body temperature of a chicken ranges from $40-42^{\circ}$ C. An important feature for enzymes effectiveness as feed additives is their ability to exhibit high activity at a given temperature. In this regard, it is necessary to study the temperature optimum of enzymes [9]. It was found that their maximum activity phytases exhibited at $37^{\circ} \mathrm{C}$. The level of phytase activity at $25^{\circ} \mathrm{C}$ and $50^{\circ} \mathrm{C}$ was similar to that at the optimum temperature, only slightly decreasing. With an increase in temperature to $80^{\circ}$ $\mathrm{C}$, the activity of recombinant phytases decreased by $15 \%$. 


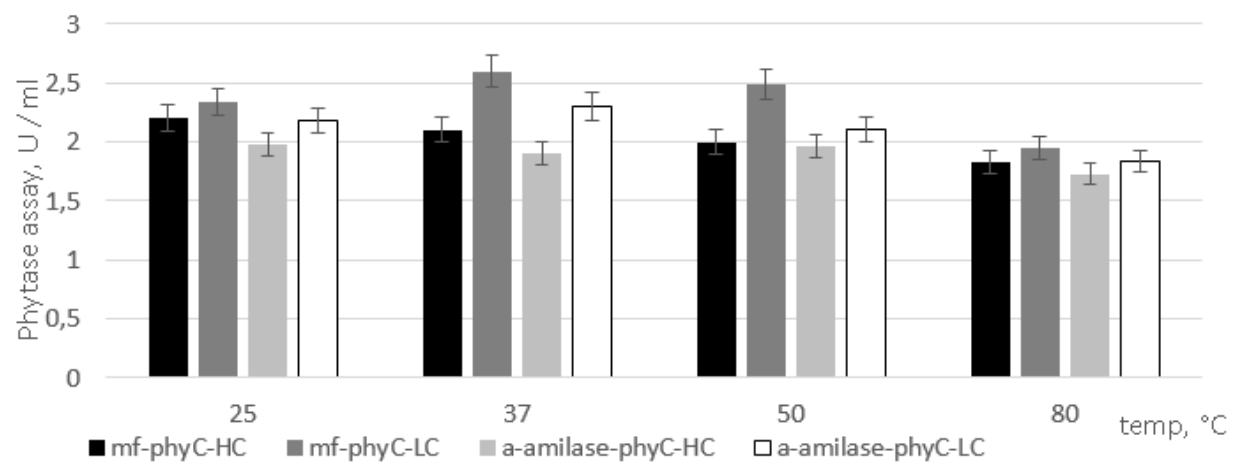

Fig. 3.Temperature optimum of recombinant phytases. The enzyme activity at $37^{\circ} \mathrm{C}$ was taken as $100 \%$.

In their study, M. Guerrero-Olazarán et al, studying the properties of the native and recombinant enzymes of $B$. Subtilis VTT E-68013, found that the optimal temperature for both phytases was from 55 to $70^{\circ} \mathrm{C}[6]$.

All recombinant enzymes were highly active over a wide temperature range, which means they will be active at body temperature in chickens and will be capable of efficiently hydrolyze phytates in poultry.

The thermal stability of Bacillus phytases in the high temperature range, from 60 to $95^{\circ}$ $\mathrm{C}$, is another important and useful feature for their use as feed additives for animals, since steam and high temperatures are used at the pelletizing process [6]. Despite the fact that alternative technologies allow phytases to be sprayed onto feed after pelleting, which avoids thermal denaturation of the enzyme, thermostable phytases are still more preferable candidates for use as feed additives [10]. We studied the effect of temperature on the stability of enzymes in the range from $-80^{\circ} \mathrm{C}$ to $90^{\circ} \mathrm{C}$, incubated for 1 hour. It was found that all phytases retained their activity in the range from -80 to $50{ }^{\circ} \mathrm{C}$. When the temperature was raised to $90^{\circ} \mathrm{C}$, the enzymes retained more than $90 \%$ of their activity (Figure 4). Thus, it can be concluded that the enzymes are stable over a wide temperature range.

The MF-phyC-LC enzyme exhibited the highest activity at all temperatures, while aamylase-phyC-HC exhibited the least activity. The enzymes MF-phyC-HC and a-amylasephyC-LC exhibited the same activity.

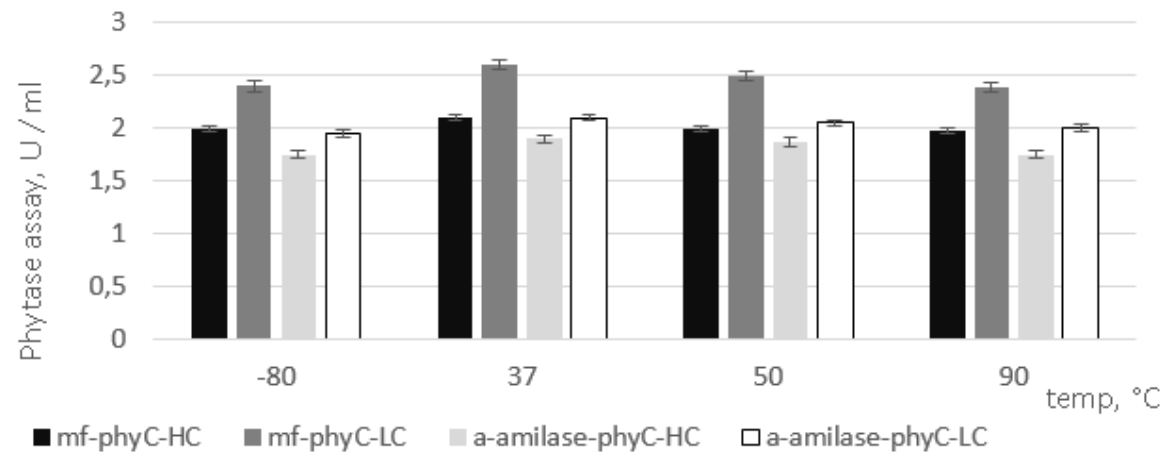

Fig. 4. Thermostability of recombinant phytases, the activity of enzymes incubated at $37^{\circ} \mathrm{C}$ was taken as $100 \%$. 
Guerrero-Olazarán compared the efficiency of FTEII phytase with three commercial phytases in terms of thermal stability at $99^{\circ} \mathrm{C}$. The FTEII enzyme showed the highest thermal stability with a residual activity of $82 \pm 3$ after $1.5 \mathrm{~min}$ of treatment at $90^{\circ} \mathrm{C}$ [6].

Based on the foregoing, it can be concluded that recombinant enzymes have high thermal stability both at negative and positive temperatures, which will allow them to undergo the feed pelletizing process without significant loss of enzymatic activity.

Thus, in the course of this work, such characteristics of four recombinant phytases as $\mathrm{pH}$ stability, temperature optimum and thermal stability were investigated and compared (Table 1).

Table 1. Enzymatic properties of phytases.

\begin{tabular}{|c|c|c|c|c|}
\hline Properties & $\begin{array}{c}\text { MF- } p h y C- \\
\text { HC }\end{array}$ & $\begin{array}{c}\text { MF-phyC- } \\
\text { LC }\end{array}$ & $\begin{array}{c}\text { a-amylase- } \\
\text { phyC-HC }\end{array}$ & $\begin{array}{c}\text { a-amylase- } \\
\text { phyC-LC }\end{array}$ \\
\hline pH stability $(\geq 80 \%$ activity) & $2.5-9.0$ & $2.5-9.0$ & $5.5-9.0$ & $2.5-9.0$ \\
\hline Temperature optimum & 37 & 37 & 37 & 37 \\
\hline Thermal stability in\% & & & & \\
$(1$ h) at: & 95 & 92 & 92 & 93 \\
$-80^{\circ} \mathrm{C}$ & 100 & 100 & 100 & 100 \\
$37^{\circ} \mathrm{C}$ & 94 & 92 & 92 & 95 \\
$90^{\circ} \mathrm{C}$ & & & & \\
\hline
\end{tabular}

\section{Conclusions}

Based on the analysis of all the characteristics of proteins, it can be concluded that all the obtained enzymes have similar properties. The MF-phyC-LC enzyme is the most stable in a wide $\mathrm{pH}$ range, has the highest activity and stability in the temperature range from -80 to 90 ${ }^{\circ} \mathrm{C}$ compared to other phytases, which makes it the most preferred as a feed additive. An increase in the thermostability of the recombinant enzymes in comparison with the native protein was found, which is probably associated with the process of glycosylation. This is a significant advantage in the industrial production of enzymes. Considering that all phytases were obtained in the same $P$. pastoris expression system, it can be assumed that the differences in the activity and stability of phytases are due to the choice of the vector or signal sequence. Probably, the signal peptide $\alpha$-mating factor promotes better secretion of the enzyme into the extracellular environment.

It was found that the recombinant strains pPINK-LC- $\alpha-M F-p h y C, p P I N K-H C-\alpha$-amyl phyC, pPINK-LC- $\alpha$-amyl -phyC, pPINK-HC- $\alpha$-MF -phyC of the P. pastoris yeast are able to synthesize and to secrete $B$. ginsengihumi M 2.11 bacterial phytase phyC. The maximum activity was observed in the pPINK-LC- $\alpha$-MF strain. Recombinant phytases from $B$. ginsengihumi M 2.11 exhibited high activity in a wide $\mathrm{pH}$ range from 2.5 to 9.0. The MFphyC-HC construction is $\mathrm{pH}$ stable. The temperature optimum corresponds to $37^{\circ} \mathrm{C}$, the recombinant phytases retain their activity in the range from -80 to $90^{\circ} \mathrm{C}$.

\section{Acknowledgments}

The reported study was funded by RFBR, project number № 19-38-90208.

\section{References}

1. R.S. Gibson, V. Raboy, J.C. King, Nutr Rev. 76, 793-804 (2018) 
2. E. R. Graminho, N. Takaya, A. Nakamura, T. Hoshino, J Gen Appl Microbiol 61,15-23 (2015)

3. J. Hirvonen, J. Liljavirta, M.T. Saarinen, M.J. Lehtinen, I. Ahonen, P. Nurminen, J Agric Food Chem, 67, 11396-11402 (2019)

4. R. Greiner, U. Konietzny, In Enzymes in Farm Animal Nutrition 96-128 (2010)

5. J.M. Viader-Salvado, J. Gallegos López,J Gerardo Carreón-Trevino, Martha GuerreroOlazaran, Applied and Environmental Microbiology 76, 19 (2010)

6. M. Guerrero-Olazarán, L. Rodríguez-Blanco, J.G. Carreon-Treviño, J.A. GallegosLopez, J.M. Viader-Salvado, Appl Environ Microbiol, 76, 16, 5601-5608 (2010)

7. M. Herrmann, C.-E. Wegner, M. Taubert, P. Geesink, K. Lehmann, L. Yan, et al. Front Microbiol 10, 1407, (2019)

8. A.P. Nichaev., S. E. Trauberng, A. A. Kochetkova, 640 (SPb: GIORD, 2007) ISBN 598879-011-9

9. O. Raretooth, Compound feed 12, 71-74 (2014)

10. O. V. Trufanov, 112 (Kiev: PolygraphInko, 2011) 